\title{
Bursa-Kestel Ormanlarında Çap Dağılımlarının Weibull Fonksiyonu ile Modellenmesi
}

\author{
Ferhat BOLAT $^{1^{*}}$ ilker ERCANLI ${ }^{1}$ \\ ${ }^{1}$ Çankırı Karatekin Üniversitesi Orman Fakültesi Orman Müh. Bölümü, Çankırı, Türkiye \\ *Sorumlu yazar: fbolat@karatekin.edu.tr
}

Geliş Tarihi: 02.05.2016

Kabul Tarihi: 13.02.2017

Özet: Orman işletmelerinin uzun dönemli ekonomik ve silvikültürel değerlendirmelerinin yapılabilmesi için meşcereler hakkında detaylı bilgilere ihtiyaç duyulmaktadır. Çap dağılım modelleri, meşcere ağaç sayısı, göğüs yüzeyi ve hacminin çap sınıfları düzeyinde elde edilmesine imkân sunmaktadır. Böylece, hem silvikültürel müdahalelerin meşcere yapıları üzerine etkisi hem de orman işletmelerinin ekonomik analizi daha detaylı yapılabilmektedir. Bu çalışmada çap dağılımları üç parametreli Weibull fonksiyonu ile tahmin edilmiştir. Weibull fonksiyonuna ilişkin parametreler; maksimum olabilirlik ile dağılımın belirli yüzdeliklerini esas alan eşitliklere dayanan farklı yöntemler kullanılarak tahmin edilmiştir. Farklı parametre tahmin yöntemlerini karşılaştırmak üzere Reynolds hata indeks değerine göre yapılan karşılaştırmalarda; \%31 ve \%63'lük değerlerini esas alan yöntem, 2.61 ortalama başarı sırası ile Weibull fonksiyonuna ilişkin parametrelerin tahmin edilmesinde en başarılı yöntem olarak belirlenmiştir. En başarılı olarak belirlenen bu yöntem ile tahmin edilen dağılımın örnek alanlardaki çap dağılımına uygunluğu Kolmogorov-Simirnov analizine göre test edilmiş olup sonuçlara göre Weibull fonksiyonu 312 örnek alanın 305'inde istatistiksel olarak uygun bulunmuştur.

Anahtar kelimeler: Çap dağılımı, 3 parametreli Weibull, Olasılık yoğunluk fonksiyonu, meşcere yapısı

Modeling Diameter Distributions by Using Weibull Function in Forests Located Kestel-Bursa

Abstract: Detailed data about forest stands are needed for economic and silvicultural interpretation of forest enterprises for a long time. Diameter distribution models (DDMs) allow to predict number of trees, basal area and stand volume at level of diameter classes. So, both effects of silvicultural treatments on forest stands and economic analysis of forest enterprise can be made with more details. In this study, diameter distributions were predicted by three-parameter Weibull function. The parameters of the Weibull function were predicted by maximum likelihood and percentile-based methods. According to the comparison based on Reynold's error index, the method based on $31^{\text {th }}$ and $63^{\text {rd }}$ percentiles with an average success order of 2.61 was assessed as the most successful in prediction of parameters of the Weibull function. The eligible of the predicted distribution by the most successful method for the observed distribution was tested by Kolmogorov-Simirnov analyze, and the results showed that the Weibull function was suitable for 305 of total 312 sample plots.

Key words: Diameter distribution, 3-parameter Weibull, probability density function, stand structure

\section{Giriş}

Ormancılık bilimi açısından artım ve büyüme modelleri, çeşitli koşullar altındaki meşcerelerin artım ve büyüme değerlerini tahmin eden denklem sistemleridir (Vanclay, 1994; Misır, 2003). Söz konusu bu modeller, silvikültürel işlem seçeneklerinin, meşcere artım ve büyüme değerlerinin tahmin edilmesi ve bir meşcereden elde edilebilecek odun hasılasının belirlenmesinde yaygin olarak kullanılmaktadırlar (Akalp, 1982).

Meşcerelerin artım ve büyüme ilişkilerinin ve meşcere parametrelerinin uzun süreli değişimlerini tahmin eden modeller; modellendiği birime göre meşcere, tek ağaç ve çap dağ 1 lım modelleri olmak üzere üç farklı düzeyde geliştirilirler (Zhang ve Lei, 2010). Ülkemizde genellikle orman amenajman planlarının hazırlanmasında, optimal kuruluşun belirlenmesinde, artım ve büyüme değerlerinin tahmin edilmesinde hasilat tablosu olarak bilinen tam meşcere modelleri kullanılmaktadır. Ancak, hasılat tabloları, meşcere ağaç sayısı, meşcere gögüs yüzeyi ve meşcere hacmi gibi meşcerenin tümü için tahminler sunduğundan meşcere yapıları hakkında daha detaylı bilgiler sağlayamamaktadırlar. Tek ağaç modelleri ise meşcere yapıları hakkında detaylı bilgiler 
sunmasına rağmen modelde yer alan değişkenlerin genel orman envanter çalışmalarında elde edilememesi ve verilerin toplanması sürecinde daha yoğun emek, daha fazla iş gücü ve daha çok zaman gerektirmesi bakımından uygulamada yer bulamamaktadır. Çap dağılım modelleri ise diğer iki modelle kıyaslandiğında, modelde yer alan değişkenlerin genel envanter çalıșmalarında rahatlıkla elde edilmesi ve bir meșcereden elde edilebilecek ürün çeșitlerinin tahmin edilmesine imkan sağlamaları ile öne çıkmaktadır (Bolat, 2015)

Orman işletmelerinin ekonomik analizlerinin verimli bir şekilde yapılabilmesi için meşcerenin tümü yerine, belirli çap aralığındaki tahminlere ihtiyaç vardır. Çünkü ormanlardan elde edilecek ürünlerin ekonomik değerini belirleyen temel faktörlerden birisi de, bu ürünlerin hangi çap değerinde elde edildiğidir. $\mathrm{Bu}$ amaçla, belirli bir çap değerinden sonra ya da belirli bir çap aralığına kadar veya iki çap değeri arasında alınabilecek hacim ve hacim elemanları, çap dağılım modelleri ile tahmin edilmektedir. Çap dağılım modellerinin geliştirilmesi sürecinde özellikle 1960'l1 yıllardan itibaren istatistik biliminin temel konularından birisi olan olasılık yoğunluk fonksiyonları kullanılmaya başlanmıştır (Packard 2000). Ormancılık çalışmalarında çap dağılım modellerinin oluşturulmasında yaygın olarak kullanılan olasılık yoğunluk fonksiyonlar1: Johnson's SB (Johnson, 1949), Weibull (Weibull, 1951), Gamma (Nelson, 1964), Log-normal (Bliss ve Reineker, 1964) ve Beta (Clutter ve Bennet, 1965) fonksiyonu olarak sıralanabilir. Ancak son zamanlarda çap dağılımı konusunda yapılan araştırmalar, bir dağılıma ilişkin konum, şekil ve ölçek parametrelerini içeren Weibull fonksiyonunun farklı kuruluşlardaki meşcerelerin çap dağılımlarını temsil etmede diğer yöntemlere göre daha başarılı olduğunu ortaya koymuştur (Podlaski ve Zasada, 2008; Ercanlı ve Yavuz, 2010; Sakıc1 ve Gülsunar, 2012; Sönmez ve ark. 2015). Günümüzde Weibull fonksiyonunun üstünlügü kabul edilmiş ve olasılık yoğunluk fonksiyonlarına ait parametrelerin hangi yöntemlerle daha iyi tahmin edileceği çalıșmalara konu edilmektedir. Ormancılık çalışmalarında çap dağılım fonksiyonlarının parametreleri, maksimum olabilirlik (Zarnoch ve Dell, 1985; Özdemir, 2015; Bolat, 2015), moment (Lei, 2008) ve hibrid yöntemi (Liu ve ark., 2013) ile dağılımın yüzdelik değerlerini esas alan yöntemle (Borders ve ark., 1987; Bolat, 2015) tahmin edilmektedir. Ancak birçok çalışmada çap dağılımlarının yüzdelik değerlerini esas alan yöntemlerin biyolojik kanuniyetleri açıklamada daha başarılı oldukları belirtilmektedir (Borders ve ark., 1987; Knowe ve ark., 1997; Maltamo ve ark., 2000; Liu ve ark., 2004; Gorgoso-Varela, 2015). Bu çalışmada farklı ağaç türlerini bir arada içeren eşit yaşlı saf ve karışık meşcerelerde çap dağılımlarının (i) Weibull fonksiyonu ile modellenmesi, (ii) maksimum olabilirlik yöntemi ile dağılımların çeşitli yüzdeliklerini kullanan eşitlikleri esas alan parametre tahmin yöntemlerinin çap dağılımlarını modellemedeki başarılarının karşılaştırılması amaçlanmaktadır.

\section{Materyal ve Metot Materyal}

$\mathrm{Bu}$ çalışmada kullanılan veriler, Bursa Orman İşletme Müdürlüğü'ne bağlı Kestel Orman İşletme Şefliği sınırları içerisindeki ormanlarda gerçekleştirilmiş orman envanterine ilişkin verilerden elde edilmiştir (Bolat, 2015) (Şekil 1) 


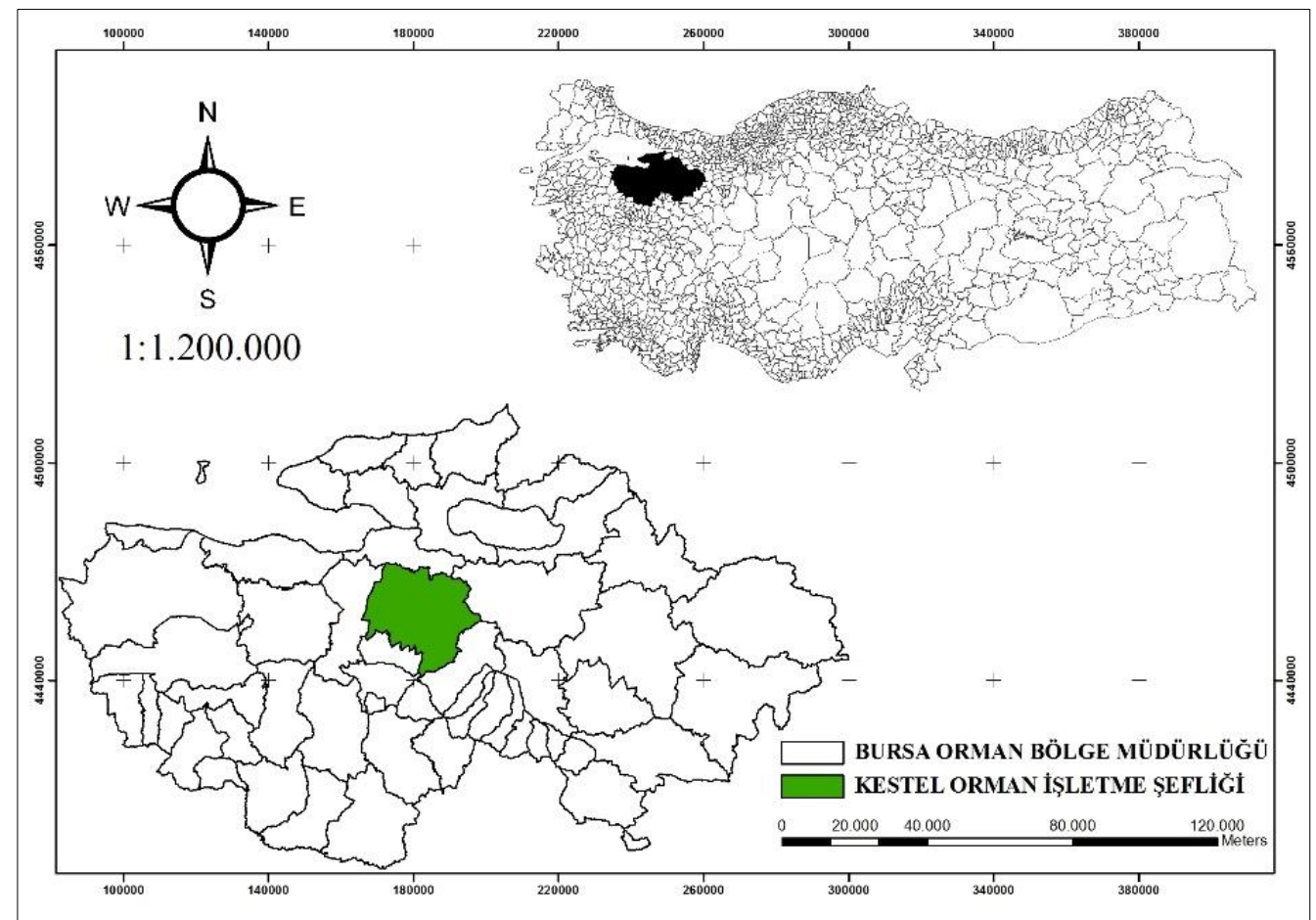

Şekil 1. Çalışma alanı

Tablo 1. Meşcere tipi düzeyinde göğüs çapına $\left(\mathrm{d}_{1.3}\right)$ ait tanımlayıcı istatistikler

\begin{tabular}{lcccccccc}
\hline Rumuz & $\begin{array}{c}\mathrm{N} \\
(\mathrm{adet})\end{array}$ & $\begin{array}{c}\text { Minimum } \\
(\mathrm{cm})\end{array}$ & $\begin{array}{c}\text { Maksimum } \\
(\mathrm{cm})\end{array}$ & $\bar{X}(\mathrm{~cm})$ & $\mathrm{S}$ & $C_{v}(\%)$ & $\begin{array}{c}\text { Basıklik } \\
\text { Katsayıs1 } \\
(\mathrm{BK})\end{array}$ & $\begin{array}{c}\text { Çarpıkl1k } \\
\text { Katsayıs1 } \\
(\mathrm{ÇK})\end{array}$ \\
\hline Çk & 36 & 8.0 & 65.0 & 18.9 & 10.1 & 53.7 & 1.1 & 0.9 \\
ÇkM & 23 & 8.0 & 63.0 & 15.1 & 8.6 & 57.2 & 1.6 & 2.8 \\
Çz & 52 & 8.0 & 65.0 & 19.3 & 9.5 & 49.3 & 1.0 & 0.8 \\
$\mathrm{G}$ & 25 & 8.0 & 72.0 & 19.1 & 9.0 & 47.2 & 1.1 & 1.9 \\
$\mathrm{GKn}$ & 38 & 8.0 & 120.0 & 17.9 & 10.8 & 60.3 & 2.7 & 14.7 \\
$\mathrm{Kn}$ & 62 & 8.0 & 147.0 & 15.7 & 8.2 & 52.0 & 3.4 & 29.2 \\
$\mathrm{KnÇk}$ & 23 & 8.0 & 67.0 & 14.0 & 7.5 & 53.3 & 2.6 & 9.9 \\
$\mathrm{KnG}$ & 53 & 8.0 & 90.0 & 17.1 & 9.4 & 55.2 & 2.3 & 8.5 \\
\hline
\end{tabular}

$\mathrm{N}=$ Her bir meşcere tipinin toplam örnek alan sayıs1, $\bar{X}=$ Meşcere tipi düzeyinde aritmetik ortalama göğüs çapı $\left(\mathrm{d}_{1.3}\right)$ değeri, $\mathrm{S}=$ Standart sapma, $C_{v}=$ Varyasyon katsayısı.

Çk= Karaçam, Çz= Kızılçam, $\mathrm{G}=$ Göknar, $\mathrm{Kn}=$ Kayın, $\mathrm{M}=$ Meşe.

ÇK $<0$ (sola çarpık dağılım), ÇK $>0$ (sağa çarpık dağılım), ÇK=0 normal dağılım.

$\mathrm{BK}<3$ (yayvan tepeli dağ $1 \mathrm{lım}$ ), $\mathrm{BK}>3$ (sivri tepeli dağ $11 \mathrm{~m}$ ), $\mathrm{BK}=0$ (normal tepeli dağ $11 \mathrm{~m}$ ) 
Çalışma alanının deniz seviyesinden yüksekliği ortalama $1250 \mathrm{~m}$ olup, $29^{\circ} 13^{\prime} 00^{\prime \prime}$ $29^{\circ} 21^{\prime} 54^{\prime \prime}$ doğu boylamları ile $40^{\circ} 00^{\prime} 00^{\prime \prime}-40^{\circ}$ $12^{\prime} 10^{\prime \prime}$ kuzey enlemleri arasında yer almaktadır. Çalışma alanında Karadeniz iklimi hakim olup, aylık ortalama sicaklıklar $-1.8{ }^{\circ} \mathrm{C}$ ile $24.6{ }^{\circ} \mathrm{C}$ arasında ve yıllık ortalama yağış $800 \mathrm{~mm}$ ile $1020 \mathrm{~mm}$ arasında değişmektedir.

Çalışmada kullanılan veriler saf ve karışık ormanlardan alınmıș 312 adet örnek alandan oluşmaktadır (OGM, 2005). Söz konusu örnek alanlarda yayılış yapan ağaç türleri Karaçam (Pinus nigra J.F. Arnold), Kızılçam (Pinus brutia Ten.), Göknar (Abies bornmülleriana Mattfeld), Kayın (Fagus orientalis Lipsky), Meşe (Quercus petraea (Mattuschka) Liebl.) dir.

Çalışmada kullanılan göğüs çapına ilişkin verilere ait çeşitli tanımlayıcı istatistikler Tablo 1 'de verilmiştir. Çalışmaya konu her bir meşcere tipinin gelişim çağları düzeyinde örnek alan sayılarının dağılımına ilişkin bilgiler Tablo 2'de verilmiștir. Söz konuşu meșcerelerin \%79.5'i üç kapalı (kapalılık>\%70), \%19.6'sı iki kapalı (\%40-\%70) ve \%1'i bir kapalı (\%11$\% 40)$ 'dir.

\section{Metot}

Ağaçların çap basamaklarına dağılımlarının tahmin edilmesinde üç parametreli Weibull olasılık yoğunluk fonksiyonu kullanılmıştır.

$F(x, \alpha, \beta, \gamma)=\frac{\gamma}{\beta} \cdot\left(\frac{x-a}{\beta}\right)^{\gamma-1} * \exp \left(-\left(\frac{x-a}{\beta}\right)^{\gamma}\right)$

Burada:

$\mathrm{x}$ : Çap değeri

$\alpha$ : Konum parametresi

$\beta$ : Ölçek parametresi

$\gamma$ : Şekil parametresi

Weibull fonksiyonunun konum parametresi ( $\alpha)$ dağılımın başlangıç noktasını, ölçek parametresi $(\beta)$ dağılımın basıklığını, şekil parametresi $(\gamma)$ ise çarpıklığını tanımlamaktadır.
Tablo 2. Meşcere tipi düzeyinde gelişim çağlarına göre örnek alan sayılarının dağılımı

\begin{tabular}{|c|c|c|c|}
\hline Mesçere Tipi & $\begin{array}{l}\text { Gelişim } \\
\text { Çağları }\end{array}$ & $\mathrm{n}$ & $\mathrm{n}(\%)$ \\
\hline \multirow{4}{*}{ Çk } & $\mathrm{bc}$ & 6 & 16.7 \\
\hline & $\mathrm{c}$ & 21 & 58.3 \\
\hline & $\mathrm{cd}$ & 8 & 22.2 \\
\hline & $\mathrm{d}$ & 1 & 2.8 \\
\hline \multirow{2}{*}{ ÇkM } & $\mathrm{b}$ & 7 & 30.4 \\
\hline & $\mathrm{c}$ & 16 & 69.6 \\
\hline \multirow{4}{*}{$\mathrm{Çz}$} & $\mathrm{b}$ & 1 & 1.9 \\
\hline & $\mathrm{bc}$ & 12 & 23.1 \\
\hline & $\mathrm{c}$ & 34 & 65.4 \\
\hline & $\mathrm{d}$ & 5 & 9.6 \\
\hline $\mathrm{G}$ & $\mathrm{c}$ & 25 & 100 \\
\hline \multirow{3}{*}{ GKn } & $\mathrm{bc}$ & 5 & 13.2 \\
\hline & $\mathrm{c}$ & 22 & 57.9 \\
\hline & $\mathrm{cd}$ & 11 & 28.9 \\
\hline \multirow{5}{*}{$\mathrm{Kn}$} & $\mathrm{b}$ & 7 & 11.3 \\
\hline & $\mathrm{bc}$ & 19 & 30.6 \\
\hline & $\mathrm{c}$ & 26 & 41.9 \\
\hline & $\mathrm{cd}$ & 4 & 6.5 \\
\hline & $\mathrm{d}$ & 6 & 9.7 \\
\hline \multirow{2}{*}{$\mathrm{KnÇk}$} & $\mathrm{bc}$ & 22 & 95.7 \\
\hline & $\mathrm{c}$ & 1 & 4.3 \\
\hline \multirow{4}{*}{$\mathrm{KnG}$} & $\mathrm{bc}$ & 12 & 22.6 \\
\hline & $\mathrm{c}$ & 24 & 45.3 \\
\hline & $\mathrm{cd}$ & 8 & 15.1 \\
\hline & $\mathrm{d}$ & 9 & 17.0 \\
\hline
\end{tabular}

n: Her bir meşcere tipi içerisindeki farkı gelişim çağlarına ilişkin örnek alan sayıları

Gelişim çağları: $b=$ sırıklık-direklik, $c=$ ince, $d:=$ orta ve kalın ağaçlık çağı

\section{Parametre tahmin yöntemleri}

Weilbul fonksiyonuna ait $\beta$ ve $\gamma$ parametrelerinin tahmin edilmesinde maksimum olabilirlik yöntemi ile çap dağılımının farklı yüzdeliklerini kullanan eșitlikleri esas alan yöntemler kullanılmıștır (Tablo 3). a parametresi ise, her bir örnek alandaki minimum çapın yarısı olarak alınmıştır (Frazier, 1981).

\section{Maksimum olabilirlik yöntemi}

Maksimum olabilirlik yöntemi ile $\beta$ ve $\gamma$ parametre değerlerinin tahmin edilmesinde SAS 9.0 istatistik yazılımındaki CAPABILITY 
prosedürü kullanılmıştır. Maksimum olabilirlik yöntemine ilişkin eşitlikler:

$$
\begin{aligned}
& \frac{\sum_{i=1}^{n}\left(x_{i}-a\right)^{\gamma} \ln \left(x_{i}-a\right)}{\sum_{i=1}^{n}\left(x_{i}-a\right)^{\gamma}}-\frac{1}{\gamma}=\frac{1}{n} \sum_{i=1}^{n}\left(x_{i}-a\right) \\
& \beta=\left(\frac{1}{n} \sum_{i=1}^{n}\left(x_{i}-a\right)^{\gamma}\right)^{\frac{1}{\gamma}}
\end{aligned}
$$

Burada;

n: örnek gözlem sayısı

$\mathrm{x}_{\mathrm{i}}$ : i. çap basamağının orta değeri

Tablo 3. Parametre tahmininde kullanılan yüzdelik değerler ve eşitlikler

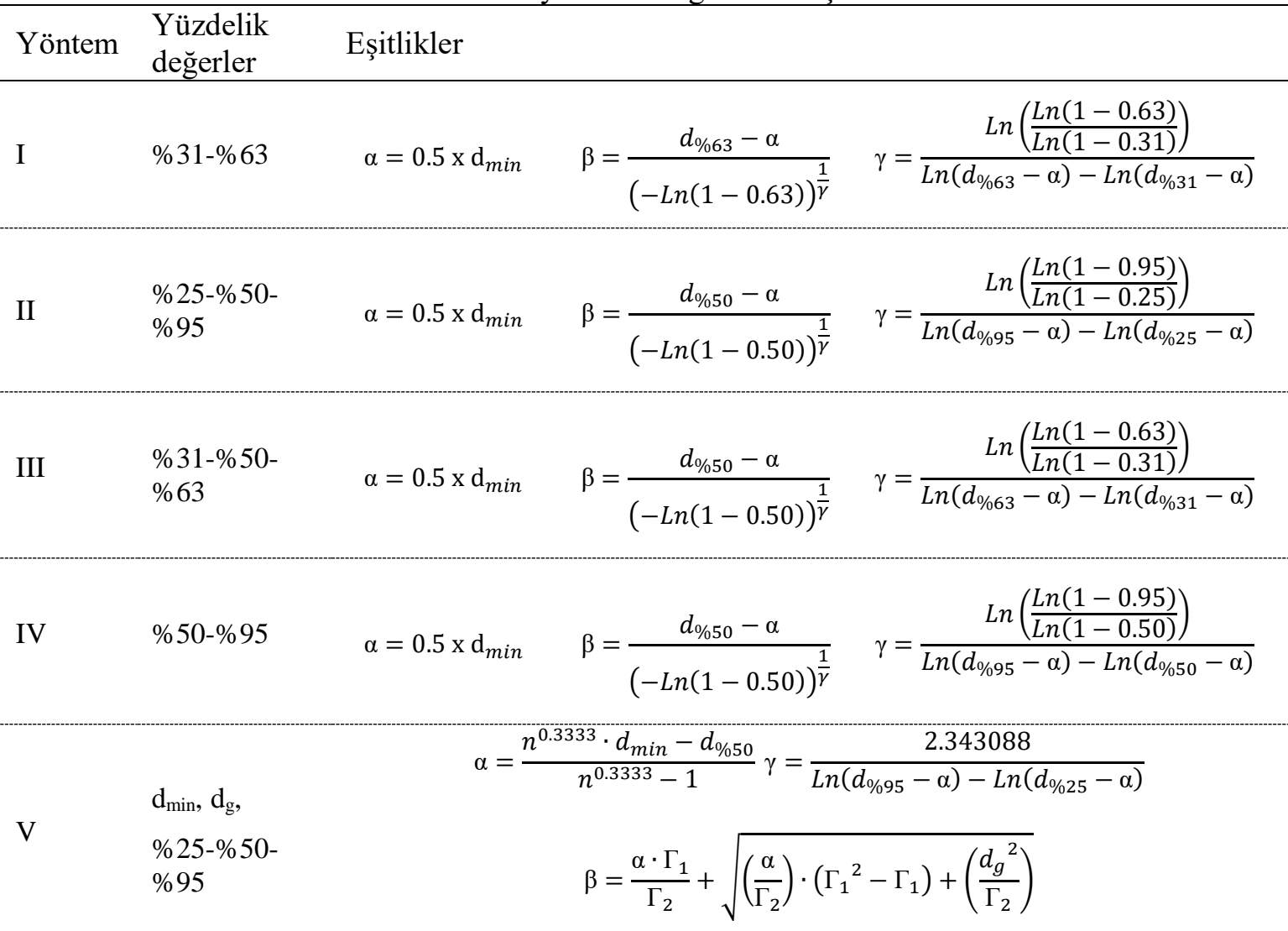

$\mathrm{n}=$ her bir örnek alandaki ağaç sayısı $\mathrm{d}_{\min }$ her bir örnek alandaki minimum çap, $\mathrm{d}_{\mathrm{g}}=$ her bir örnek alan için hesaplanan göğüs yüzeyi orta ağacının çap1, $\mathrm{d} \% 25, \mathrm{~d} \% 31, \mathrm{~d} \% 50, \mathrm{~d} \% 63, \mathrm{~d} \% 95=$ verileri küçükten büyüğe doğru siralandığında \%25'lik, $\% 31$ 'lik, \%50'lik, \%63'lik ve \%95'lik veriye karşılık çap değeri, $\Gamma_{1}=\Gamma\left(1+\frac{1}{\gamma}\right), \Gamma_{2}=\Gamma\left(1+\frac{2}{\gamma}\right)$

\section{Yüzdelik değerleri esas alan yöntem}

Yüzdelik değerleri esas alan yöntemler ile $\beta$ ve $\gamma$ parametrelerini tahmin etmek için çap dağılımının belirli yüzdeliklerine karşılık gelen çap değerlerini esas alan eşitliklere dayanmaktadırlar. $\mathrm{Bu}$ çalışmada, yüzdelik değerleri esas alan yöntemler olarak; I. yöntemde $\% 31-\% 63$, II. yöntemde $\% 25-\% 50$ $\% 95$, III. yöntemde $\% 31-\% 50-\% 63$, IV. yöntemde \%50-\%95 ve V. yöntemde ise, minimum çap, göğüs yüzeyi orta ağacının çapı (dg) ile \%25-\%50-\%95'lik değerlerine karşıllk gelen çap değerleri kullanılmaktadır. $\mathrm{Bu}$ çalışmada kullanılan 5 farklı yüzdelik yöntemine ilişkin eşitlikler Tablo 3'de verilmiştir. 


\section{Parametre tahmin yöntemlerinin karşılaştırılması}

Parametre tahmin yöntemlerinden çalışmaya konu meşcerelerin çap dağılımların modellemede en başarılı olanını belirlemek için Reynolds ve ark. (1988) tarafından geliştirilen hata indeks değeri kullanılmıştır.

$$
e=\sum_{i=1}^{m}\left|N_{\text {ölçülen }}-N_{\text {tahmin }}\right|
$$

Burada;

$e$ : Hata değeri

$\mathrm{N}$ : Ağaç sayısı

Her bir örnek alandaki en küçük hata değerine sahip olan yöntem, meşcerelerin çap dağ 1 lımını temsil etmede 1 . sirayı alırken, hata değerinin büyüklügüne göre diğer yöntemler 2 ., 3., 4., 5. ve 6. sırayı almıştır. Bu şekilde her bir örnek alan için parametre hesaplama yöntemlerine karşılık gelen başarı sıralarının toplamı alınmış ve en küçük ortalama başarı sırasına sahip olan yöntem çalışma alanındaki meşcerelerin çap dağılımlarının modellenmesinde en başarılı olarak belirlenmiştir. Çok sayıda örnek alan olması nedeniyle parametre tahmin yöntemlerinin her bir örnek alanlardaki başarı sırası ayrı ayrı verilememiştir. Bunun yerine, kısaca bir yöntemin kaç kez 1., 2., 3., 4., 5. ve 6. olduğu belirtilmiștir (Tablo 4 ve Şekil 2). En başarılı olarak belirlenen parametre tahmin yöntemiyle oluşturulan üç parametreli Weibull olasıllk yoğunluk fonksiyonunun istatistiksel olarak örnek alanlara uygunluğu KolmogorovSimirnov analizi (K-S) ile test edilmiștir. K-S analizine ilişkin hesap değeri; çap basamağı düzeyinde hesaplanan iki oransal birikimli frekanslara ilişkin farkların en büyüğü olarak alınmıştır. Tablo değeri ise, $\% 95$ güven düzeyi için; $\quad 1.36 / \sqrt{\text { örnek alandaki ağaç sayısı }}$ olarak hesaplanmıştır. Hesap değeri tablo değerinden küçük ise geliştirilen Weibull fonksiyonun örnek alana uygun olduğu sonucuna varılir.

Tablo 4. Parametre tahmin yöntemlerinin başarı sırasına göre frekans değerleri

\begin{tabular}{ccccccccc}
\hline & & \multicolumn{7}{c}{ Başar1 Sıras1 } \\
\hline Yöntem & Örnek alan sayıs1 & 1 & 2 & 3 & 4 & 5 & 6 & Ortalama \\
\hline I & 312 & 98 & 66 & 38 & 82 & 26 & 2 & 2.61 \\
II & 312 & 58 & 41 & 57 & 94 & 52 & 10 & 3.23 \\
III & 312 & 56 & 97 & 101 & 42 & 14 & 2 & 2.57 \\
IV & 312 & 65 & 78 & 84 & 55 & 9 & 21 & 2.77 \\
V & 312 & 13 & 21 & 15 & 25 & 145 & 93 & 4.75 \\
Maksimum & 312 & 22 & 9 & 17 & 14 & 66 & 184 & 5.07 \\
Olabilirlik & 312 & & & &
\end{tabular}
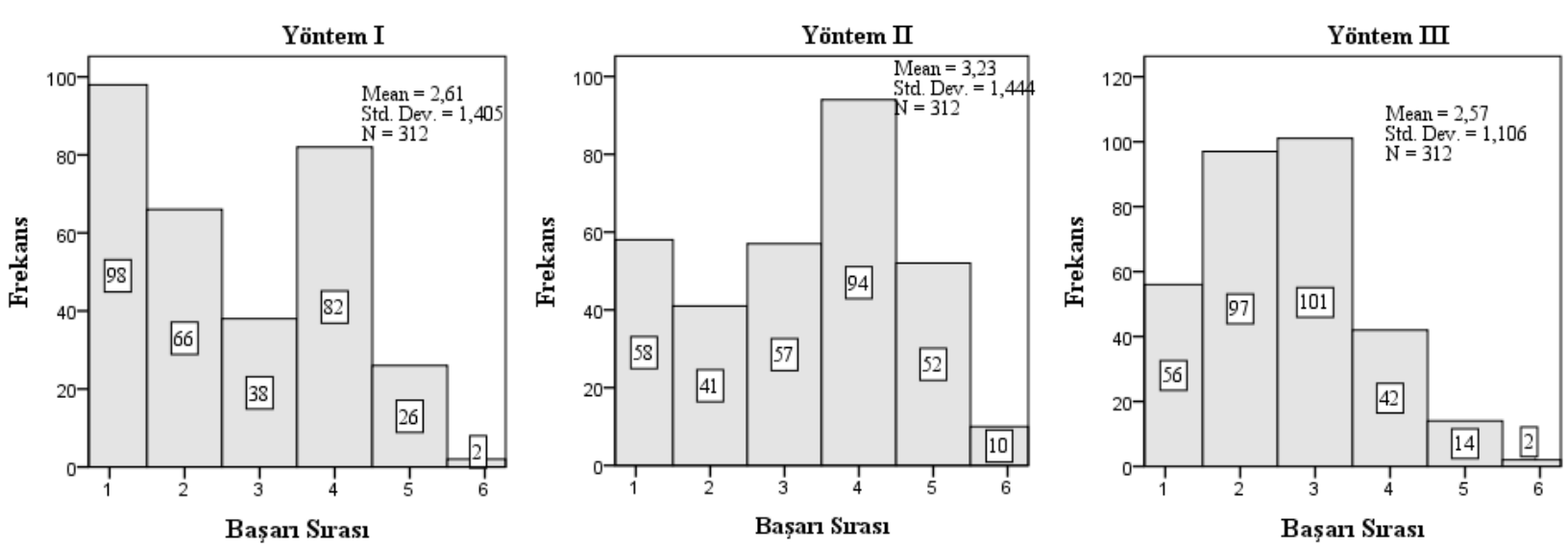

Şekil 2. Parametre tahmin yöntemlerinin başarı frekansları 


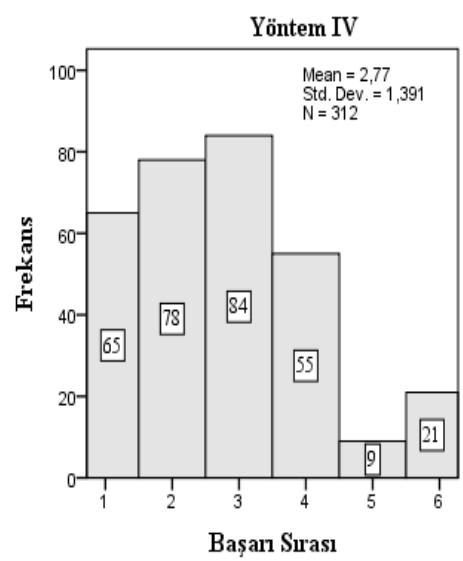

Şekil 2. (Devamı)

\section{Bulgular \\ Parametre tahmin yöntemlerine ilişkin bulgular}

Hata indeks değerine göre; maksimum olabilirlik yöntemine ilişkin ortalama başarı sırası 5.07'dır. Yüzdelik değerleri esas alan yöntemlerden I. yönteme ilişkin başarı sırası 2.61, II. yönteme ilişkin başarı sırası 3.23, III. yönteme ilişkin başarı sırası 2.57, IV. yönteme ilişkin başarı sırası 2.77 ve V. yönteme ilişkin başarı sırası 4.75 olarak elde edilmiştir (Tablo 4). Böylece, 2.60 ortalama başarı sırasına sahip olan I. yöntem çap dağılımlarını modellemede en başarıl1, maksimum olabilirlik yöntemi ise en başarısız yöntem olarak belirlenmiştir. Tahmini çap dağılımlarının örnek alanlara uygunluğu Kolmogorov-Simirnov analizi ile test edilmiş ve \%31-\%63'lük yüzdelikler ile geliştirilen Weibull fonksiyonunun $\% 95$ güvenle, 312 örnek alandan 305'inde uygun olduğu belirlenmiştir.

\section{Tartışma ve Sonuç}

$\mathrm{Bu}$ çalışmada, üç parametreli Weibull olasılık yoğunluk fonksiyonuna ilişkin parametrelerin tahmininde maksimum olabilirlik ve çap dağılımlarının çeşitli yüzdeliklerini esas alan yöntemler kullanılmıştır. Bu çalışmada kullanılan farklı parametre tahmin yöntemlerinden, Reynolds hata indeks değerine göre en başarılı olanı 2.48 ortalama başarı sırasına sahip olan Yöntem I (\%31-\%63) olarak belirlenmiştir. Benzer konuda daha önce yapılan birçok çalışmada

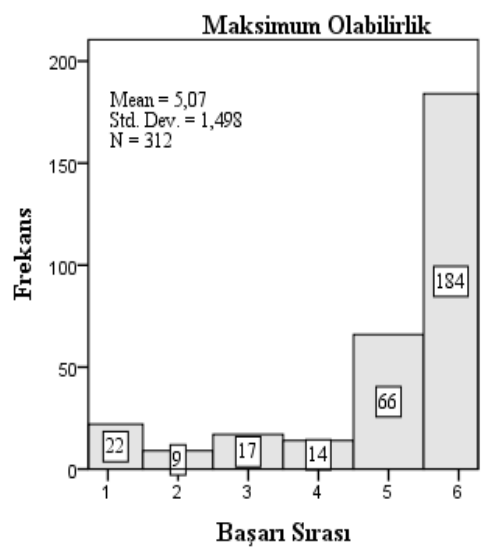

yüzdelik değerleri esas alan yöntemlerin farklı çap dağılımlarını tahmin etmede başarılı olduğu ortaya konmuştur. Örneğin, Poudel (2011) ve Karakaş (2013) çap dağılımlarının \%25-\%50$\% 95$ 'lik değerlerini esas alan yöntemin (Yöntem II) daha başarılı olduğunu belirlerken, Ercanlı ve ark. (2013) çap dağılımlarının \%25, $\% 50-\% 63$ 'lük değerleri esas alan yöntemin (Yöntem III) daha başarılı olduğunu belirlemişlerdir. Benzer şekilde, Kangas ve Maltamo (2000) Sarıçam, Ladin ve Betula meşcerelerinde yaptığı çalışmada yüzdelik değerleri esas alan yöntemlerin değişik meşcere yapılarını temsil etmede oldukça başarılı olduklarını belirtmişlerdir. Liu ve ark. (2004) ladin plantasyon ormanlarında üç parametreli Weibull fonksiyonuna ait parametrelerin yüzdelik değerleri esas alan yöntemlerle (\%25\%50-\%95) tahmin edildiğinde meşcere yapılarını temsil etmede başarı oranının arttığını bildirmişlerdir. Bir diğer çalışmada Liu ve ark. (2009) ladin plantasyonlarında yaptıkları araştırmanın sonucunda yüzdelik değerleri esas olan yöntemin (\%25-\%50-\%93) çap dağılımlarını tanımlamada daha başarılı olduğunu ortaya koymuşlardır.

Meşcere çap dağılımları meşcere yaşı, yetişme ortamı verim gücü, sıklık gibi meşcere özelliklerine, silvikültürel müdahalelerin sıklığ 1 ve şiddetine göre farklılık gösterdiğinden parametre tahmininde hangi yüzdelik değerlerin üstün olduğu meşcere yapılarına göre değişebilmektedir. 
Ülkemiz ormanları çok farklı ağaç türlerinden ve farklı yetişme ortamlarından oluşmaktadır. $\mathrm{Bu}$ nedenle, farklı yetişme ortamlarında gelişim gösteren çeşitli ağaç türlerinden oluşan meşcereler için, uygun çap dağılım modellerinin oluşturulabilmesi amacıyla çap dağılımlarını en iyi temsil eden parametre tahmin yöntemlerinin belirlenmesi önem kazanmaktadır. $\mathrm{Bu}$ nedenle parametre değerlerinin hesaplanmasında kullanılan yüzdelik değerlerin çeşitli meşcere özellikleri ile ilişkilerini modelleyen ve gelecekteki çap dağılımlarını tahmin eden eşitliklerin geliştirilmesi gerekmektedir.

\section{Teșekkür}

$\mathrm{Bu}$ çalışmada kullanılan veriler Orman Genel Müdürlüğü envanter çalışmalarından elde edilmiştir. Verilerin sağlanmasındaki yardımlarından dolayı Orman Genel Müdürlüğüne teşekkür ederiz.

\section{Kaynaklar}

Akalp T. 1982. Simulasyon tekniği ve meşcere modelleri. Journal of the Faculty of Forestry Istanbul University, 32(1), 166-172.

Bliss C.I., Reinker K.A. 1964. A lognormal approach to diameter distributions in even-aged stands. Forest Science, 10(3), 350-360.

Bolat F. 2015. Bursa-Kestel Orman İşletme Şefliği içerisindeki meşcereler için çap dağılım modellerinin geliștirilmesi. Yüksek Lisans Tezi, ÇKÜ Fen Bilimleri Enstitüsü, 77 s. Çankırı.

Borders B.E., Souter R.A., Bailey R.L., Ware K.D. 1987. Percentile based distributions characterize forest tables. Forest Science, 33(2), 570576.

Clutter J.L., Bennet F.A. 1965. Diameter distributions in old-field slash pine plantation. Georgia Forest Research Council, Report No: 13, 9p. USA.

Ercanlı İ., Yavuz H. 2010. Doğu ladini (Picea Orientalis (L.) Link)-Sarıçam (Pinus Sylvestris L.) karışık meşcerelerinde çap dağılımlarının olasılık yoğunluk fonksiyonları ile belirlenmesi. Kastamonu Orman Fakültesi Dergisi, 10(1), 68-83.

Ercanlı İ., Bolat F., Kahriman A. 2013. Comparing parameter recovery methods for diameter distribution models of Oriental spruce (Picea orientalis (L.) Link.) and Scotch pine (Pinus sylvestris L.) mixed stands located Trabzon and
Giresun Forest Regional Directorate. International Caucasian Forestry Symposium (24-26 October), 119-126, Artvin, Turkey.

Frazier J.R. 1981. Compatible whole-stand and diameter distribution models for Loblolly pine plantations. $\mathrm{PhD}$ thesis, Virginia Polytechnic Institute and State University, 125 p. Blacksburg.

Gorgoso-Varela J.J. 2015. Comparison of estimation methods for fitting Weibull distribution to the natural stand of Oluwa forest reserve, Onda State, Nigeria. Journal of Research in Forestry, Wildlife and Environment, 7(2), 81-90.

Johnson N.L. 1949. System of frequency curves generated by methods of translation. Biometrika, 36(1/2), 149-176.

Kangas A., Maltamo M. 2000. Performance of percentile based diameter distribution prediction and Weibull method in independent data sets. Silva Fennica, 34(4), 381-398.

Karakaş R. 2013. Önsen doğal Fistıkçamı (Pinus pinea L.) meşcerelerinde çap dağ 1 lımlarının modellenmesi. Yüksek Lisans Tezi, KSÜ Fen Bilimleri Enstitüsü, 67s. Kahramanmaraş.

Knowe S.A., Ahrens G.R., DeBell D.S. 1997. Comparison of diameter-distribution prediction, stand-table projection and individual-tree growth modeling approaches for young red alder plantations. Forest Ecology and Management, 98, 49-60.

Lei Y. 2008. Evaluation of three methods for estimating the Weibull distribution parameters of Chinese Pine (Pinus tabulaeformis). Journal of Forest Science, 54(12), 566-571.

Liu C., Zhang S.Y., Lei Y., Newton P.F., Zhang L. 2004. Evaluation of tree methods for predicting diameter distributions of black spruce (Picea mariana) plantations in central Canada. Canadian Journal of Forest Research, 34(12), 2424-2432.

Liu C., Beaulieu J., Prégent G., Zhang S.Y. 2009. Applications and comparison of six methods for predicting parameters of the Weibull function in the Uthinned Picea glauca plantations. Scandinavian Journal of Forest Research, 24(1), 67-75.

Maltamo M., Kangas A., Uuttera J., Torniainen T., Saramäki J. 2000. Comparison of percentile based prediction methods and Weibull distribution in describing diameter distribution of heterogenous Scots pine stands. Forest Ecology and Management 133: 263-274.

Mısır N. 2003. Karaçam ağaçlarına ilişkin büyüme modelleri. Doktora tezi, KTÜ Fen Bilimleri Enstitüsü, 209s. Trabzon. 
Nelson T.C. 1964. Diameter distribution and growth of Loblolly pine. Forest Science, 10(1), 105114.

OGM 2005. Orman envanter verileri.

Özdemir G.A. 2015. Modeling the diameter distribution of Douglas fir (Pseudotsuga menziesii (Mirb.) Franco) stands. Journal of the Faculty of Forestry Istanbul University, 66(2), 548-558.

Packard K.C. 2000. Modeling tree diameter distributions for mixed-species conifer forests in the Northeast United States. Master thesis, State University of New York, 129p. USA.

Podlaski R., Zasada M. 2008. Comparison of selected statistical distributions for modelling the diameter distributions in near-natural Abies-Fagus forests in the Swietokrzyski National Park (Poland). European Journal of Forest Research, 127(6), 455463.

Poudell K.P. 2011. Evaluation of methods to predict Weibull parameters for characterizing dimater distributions. Master Thesis, Graduate Faculty of the Louisiana State University and Agricultural and Mechanical Collage, 60p. USA.

Reynolds M.R., Thomas B.E., Won-Chin H. 1988. Goodness-of-fit tests and model selection procedures for diameter distribution models. Forest Science, 34(2), 373-399.

Sakıcı O. E., Gülsunar M. 2012. Diameter distribution of Bornmullerian fir in mixed stands. Kastamonu University, Journal of Forestry Faculty, Special Issue, 263-270.

Sönmez T., Karahalil U., Günlü A., Şahin A. 2015. Aynı yaşlı ve saf Doğu ladini (Picea orientalis (L.) Link.) meşcerelerinde çap dağılımlarının bonitet ve yaş sınıfları için değerlendirilmesi. Kastamonu Üni. Orman Fakültesi Dergisi, 15 (1), 26-36.

Vanclay J.K. 1994. Modelling forest growth: Applications to mixed tropical forests. ISBN: 0851989136, 978-0851989136, 312p. Denmark.

Weibull W. 1951. A statistical distribution function of wide applicability. Journal of Applied Mechanics, (18), 293-297.

Zarnoch S.J., Dell T.R. 1985. An evaluation of percentiles and maximum likelihood estimators of Weibull parameters. Forest Science, 31(1), 260-268.

Zhang X., Lei Y. 2010. A linkage among wholestand model, individual-tree model and diameterdistribution model. Journal of Forest Science, 56(12), 600-608. 